\title{
The Plays and Arts of Surveillance: Studying Surveillance as Entertainment.
}

\author{
Anders Albrechtslund ${ }^{1}$ and Lynsey Dubbeld ${ }^{2}$
}

\begin{abstract}
This paper suggests a direction in the development of Surveillance Studies that goes beyond current attention for the caring, productive and enabling aspects of surveillance practices. That is, surveillance could be considered not just as positively protective, but even as a comical, playful, amusing, enjoyable practice. A number of recent trends suggest that there is a potential for unmistakable entertainment in the operation of a number of contemporary surveillance practices that merit further empirical and theoretical study. The paper discusses several examples that are illustrative of these trends, such as computer games and artistic presentations. Although this analysis does not downplay the problematic and negative features of current surveillance practices, it aims to accentuate some of the ways in which surveillance-enabling technologies are able to perform entertainment functions.
\end{abstract}

\section{Introduction}

In the early days, Surveillance Studies were concerned primarily with revealing and discussing the negative implications of surveillance practices, such as their effects on the protection of civil liberties and rights. Notions and metaphors such as the Panopticon and Big Brother dominated the theoretical perspectives of the literature (Gandy, 1993; Lyon, 1994). Increasingly, students of surveillance came to consider the positive, caring aspects of surveillance as well. David Lyon (2002) among others has paid considerable attention to the protective, enabling powers of surveillance. Arguing that surveillance is Janus faced, Lyon added to the accounts of the controlling, constraining consequences of surveillance recognition of its enabling, caring features.

Undoubtedly, the recognition and understanding of the positive aspects of surveillance are still an underdeveloped area and thus a future challenge for students of surveillance. However, we suggest that another direction in the development of Surveillance Studies would be to embrace the fun features and entertainment value of surveillance. Surveillance could be considered not just as positively protective, but even as a comical, playful, amusing, enjoyable practice (Marx, 1996). A number of recent trends suggest that

${ }^{1}$ HCI Research School, Department of Communication, Aalborg University, Aalborg, Denmark. mailto:alb@hum.aau.dk

2 Department of Science, Technology, Health \& Policy Studies (STeHPS), University of Twente, Enschede, the Netherlands. mailto:L.Dubbeld@bbt.utwente.nl 
there is a potential of unmistakable entertainment in the operation of a number of contemporary surveillance practices that merit further empirical and theoretical study. This paper will discuss several examples that are illustrative of these trends, and thus explore some of the ways in which surveillance-enabling technologies are able to perform entertainment functions.

Of course, we acknowledge that there are serious problems in certain surveillance practices, and we do not wish to downplay the worrisome implications of much of today's surveillance. But this piece is an attempt to explore another side, and draw attention to a feature of surveillance that hitherto seems to be much overlooked. Moreover, it should be noted that we are aware of the manifold economic drives and politically charged motives behind entertainment-related surveillance, but these are not the subject of this paper.

\section{Surveillance, art and popular culture}

The linkage between surveillance and entertainment that we discuss in this paper is not unknown territory in arts and popular culture: surveillance was a theme in entertainment and art many years before Surveillance Studies came about as an academic field of research.

For instance, surveillance has come up as a topic in contemporary visual arts (Levin et al., 2002). To name but one example: In spring 2003, the Goethe Institute Toronto Gallery exhibited David Rokeby's media installation 'Sorting Daemon. ${ }^{3}$ Using a computer, LCD screen and camera, the installation surveys its environment (in this case a public street in Toronto), collects images of moving objects, and extracts a person's image from the background. The extracted individuals are then divided up into disaggregated patches on the basis of hue, color, and size. Eventually, the dissembled patches are reassembled and transformed into composite computer displays of alarmingly beautiful color and structure.

In addition, surveillance has been a familiar topic in modern and contemporary literature: the controlling and caring features of surveillance have been among the central motifs in famous novels by authors such as Kafka, Huxley, and Orwell. The ubiquitous Nineteen Eighty-Four is, of course, the prime example of this trend.

Similarly, movies have repeatedly displayed a preoccupation with surveillance, with directors such as Hitchcock, Coppola and De Palma, in films such as Rear Window (1954), The Conversation (1974) and Blow Out (1981) visualizing the theme of surveillance from different perspectives. In various ways, radio and TV have also embraced surveillance, from the classic 'Candid Camera' to a range of reality TV formats.

Although surveillance is a prevalent theme in art and popular culture, the artistic and media manifestations and representations of surveillance have been the subject of Surveillance Studies only to a very limited extent. Gary Marx is one of the few exceptions: as early as 1996, he discussed various examples of how surveillance issues come up in cartoons, comics and jokes, movies, pop songs, and art (Marx, 1996).

3 http://homepage.mac.com/davidrokeby/home.html 
Marx's analysis suggests that the interest of Surveillance Studies in cultural manifestations and experiences of surveillance is based on a concern with highlighting the threatening, controlling aspects of surveillance (Lyon, 2001: 51-68). Popular culture and media representations of surveillance appear to be considered as starting points for critical analyses of, for instance, the seductive powers of ominous surveillance-enabling ICTs (Rosen, 2000).

This approach is in line with artists' perspectives on surveillance, which tend to focus on controversial aspects of surveillance practices or revealing the operation of surveillance technologies. For instance, like several of Rokeby's other works, 'Sorting Daemon' was concerned with revealing the powers of vision and surveillance, and bringing to the fore the discriminatory, judgmental classifications that computers are increasingly producing as they take over human tasks of observation and monitoring. Similarly, the theatrical performances that the Surveillance Camera Players groups stage in front of public street CCTV aim to put to the test the operation and legitimacy of camera surveillance (Schienke and Brown, 2003). The design of toys that address surveillance practices, such as the Institute for Applied Autonomy's 'Little Brother,' is primarily aimed at confronting or subverting surveillance (Schienke and IAA, 2002).

However laudable and welcome these approaches to surveillance may be, in this paper we are not concerned with the subverting, critical potential of cultural reflections on surveillance. Rather, our intent is to draw attention to an emerging range of surveillance manifestations the primary purpose of which is to entertain. What's more, we do not see entertaining surveillance merely as a starting point. The entertaining side of surveillance is a phenomenon worth studying in itself, and we expect that this type of study will contribute to an understanding of the multi-faceted nature of surveillance.

\section{Surveillance games}

With the rise of home computers in the 1980s, a remarkable field of what could be called surveillance games emerged. In many video and computer games, surveillance, i.e. the tracking and tracing of objects and people through data processing technologies, became an intrinsic part of the gameplay. Increasingly, game designers purposely used the fascinating aura of surveillance - alluring and frightening at the same time - to create a stimulating gaming environment. For example, the classic, award-winning computer game 'The Sentinel' (from 1986) involves a power struggle about controlling so-called 'Synthoids' in a landscape controlled be the gaze of a 'Sentinel.' A more recent example is the simulation game 'The Sims' (put on the market in 2000), in which a 'virtual dollhouse' is controlled and cared for by the all-seeing player.

The popularization of the Internet in the 1990s created new avenues in surveillance games. Essentially, these came to employ technologies for monitoring, observing and surveying environments or people in order to create surprising, innovative and sometimes even interactive entertainment.

For example, during Tony Blair's 2005 Labour election campaign, the British newspaper 
The Guardian launched the 'Blair Watch Project' (Happold, 2005). Readers were asked to send in pictures of Blair and his fellow-campaigners while they traveled the country trying to win votes. A selection of these would be put on the newspaper's website and blog, with prizes being awarded to the most luscious photos. The aim was to collect a range of pictures that would "add up to a great snapshot of the election campaign." The website did not present the project as a means to achieve important social ideals, such as public engagement in an independent press, or reviving the oversight of democratic processes. It was primarily a call for citizens to engage in a fun race to assemble as many pictures as possible of handsome Tony and his elusive entourage.

A telling example of the mingling of surveillance and games also comes from the UK: 'Monopoly Live' is an online version of the traditional Monopoly board game that allows players to imagine playing in the real London, with London taxis acting as movers (Ogles 2005). ${ }^{4}$ While the game starts out pretty much like the traditional board game, with the buying and building of property, the online version uses 18 real London cabs equipped with GPS as movers that decide if players collect or pay rent. The game was designed to promote a new version of Monopoly, the 'Here and Now Limited Edition,' which uses contemporary landmarks of London as game-board spaces. As a marketing tool it was to run for a month during the introduction and promotion of the new product, but the game became so popular (engaging almost 167.000 players in a 24 hour period) that Hasbro Games decided to extend the campaign and to allow players to continue using the free online game for their own entertainment.

Another game that integrates a virtual environment with real life cities is Blast Theory's 'Can You See Me Now?' ${ }^{5}$ In this artistic project, Blast Theory members run through the public streets of a real city chasing to find the positions that online participants have on a parallel virtual map. Runners are equipped with handheld computers showing the positions of online players, and are able to receive messages and information. At the same time, online players can eavesdrop on their pursuers, who carry walkie-talkies that broadcast audio streams to the Internet. Although the game is presented as an artistic initiative (and has been staged at several arts festivals throughout the world), it is essentially a chase game that intimately and actively involves Internet audiences in live performances and digital broadcasting.

To sum up: in several contemporary games surveillance technologies serve as means and media for producing entertainment and interactive play. In contrast with more familiar examples of artistic and popular culture representations of surveillance, the new games do not seem to aim to criticize the legitimacy of surveillance practices. Instead, they are meant to do little else than produce excitement and diversion. The unilateral focus on fun is evident from the fact that surveillance as a theme is seldom, if at all, addressed, discussed or problematized in the games' descriptions and instructions.

\footnotetext{
4 http://www.monopolylive.com/

5 http://www.blasttheory.co.uk; http://iperg.sics.se/index swf.html
} 


\section{Conclusion}

The time has come for Surveillance Studies to recognize and take seriously the fun side of surveillance. As the examples we discussed in this paper suggest, there is a growing area of what could be called 'surveillance games' that seems to call for further analysis: games that use data processing technologies to provide or enhance entertainment, thereby appropriating surveillance devices for their own hedonistic purposes. These appropriations suggest that surveillance is not just a steady growing security industry that requires critical debate and extensive academic analysis (important as these are!); surveillance can also serve as a source of enjoyment, pleasure and fun, as is evidenced in the entertainment industry. We believe that it will be fruitful to include an analysis of the more entertaining sides of surveillance in Surveillance Studies so as to balance the academic debate on contemporary surveillance practices.

There seem to be good academic reasons for theorists to start paying attention to the entertainment value of contemporary surveillance technologies. For example, looking at surveillance from the perspective of the fun it can bring could contribute to developing analyses of how surveillance can come up in unexpected places, such as online gaming communities, and increase our sensitivity for identifying surveillance issues in innocentlooking practices such as board games.

Moreover, the concepts that surveillance scholars use in their work is most often more or less uncritically borrowed from popular culture - dystopian metaphors such as the renowned 'Big Brother' have definitely shaped the public debate on surveillance as well as research directions in Surveillance Studies. Further study of popular culture aspects of surveillance can contribute to an understanding of how we use concepts and metaphors derived from fiction in surveillance analyses. In these ways, the valuable functions of Surveillance Studies in analyzing and debating surveillance trends could become more robust and balanced. Perhaps that will be fun as well as seriously important.

\section{References}

Gandy, O. H. (1993) The Panoptic Sort: Towards a Political Economy of Personal Information. Boulder/San Francisco/Oxford: Westview Press.

Happold, T. (2005) Introducing the Blair Watch Project. 6 April 2005. Retrieved 10 August 2005, from http://blogs.guardian.co.uk/election2005/archives/2005/04/06/introducing the blair_watch_proje ct.html

Levin, T. Y. and U. Frohne, et al., eds. (2002) Ctrl[space]: Rhetorics of Surveillance from Bentham to Big Brother. Cambridge: MIT Press.

Lyon, D. (1994) The Electronic Eye: The Rise of Surveillance Society. Oxford: Polity Press.

Lyon, D. (2001) Surveillance Society: Monitoring Everyday Life. Buckingham/Philadelphia: Open University Press.

Marx, G. T. (1996) Electric eye in the sky: some reflections on the new surveillance and popular culture. In D. Lyon and E. Zureik (eds.) Computers, Surveillance and Privacy. Minneapolis/London: University of Minnesota Press, 193-233. 
Ogles, J. (2005) GPS monopoly: collect over \$200. 7 July 2005. Retrieved 10 August 2005, from http://wired-vig.wired.com/news/culture/0,1284,68023,00.html?tw=wn_7culthead

Rosen, J. (2000) The Unwanted Gaze: The Destruction of Privacy in America, New York: Vintage Books.

Schienke, E. W. and IAA (2002) On the outside looking out: an interview with the Institute for Applied Autonomy. Surveillance \& Society, 1(1): 102-119. http://www.surveillance-andsociety.org/articles1/iaa.pdf

Schienke, E. W. and B. Brown (2003) Streets into stages: an interview with Surveillance Camera Players' Bill Brown. Surveillance \& Society, 1(3): 356-374. http://www.surveillance-andsociety.org/articles1(3)/interview.pdf 